\title{
Effects of Parameters Variation in Fuzzy Based Induction Motor Drives
}

\author{
Marizan Sulaiman, Zulhisyam Salleh*, Rosli Omar \\ Faculty of Electrical Engineering, Universiti Teknikal Malaysia Melaka (UteM), \\ Hang Tuah Jaya, 76100 Durian Tunggal, Melaka, Malaysia \\ *Corresponding author, e-mail: zulhisyamsalleh@gmail.com
}

\begin{abstract}
This paper presents the effects of parameters variation over the speed response of vector controlled induction motor drives for high performance applications. The design and simulation of fuzzy logic controller are considered based on design case constant parameter fuzzy logic (DCCPFL) controller.The scaling factors for DCCPFL controller are calculated based on identified motor parameter.The performance of the DCCPFL is compared with conventional PI controller. Three different parameters is tested under no-load and loaded conditions namely rotor resistance, inertia and selfinductance. From the simulation results, it is proved that the DCCPFL have better performance in term of different parameter variations and also load disturbances. Thus the DCCPFL is appropriate to replace the conventional PI for high performance of induction motor drives system.
\end{abstract}

Keywords: fuzzy logic control, induction motor, vector control, parameters variation

Copyright $(2015$ Institute of Advanced Engineering and Science. All rights reserved.

\section{Introduction}

The induction motor is the motor of the choice in several industrial application due to its reliability, power to size ratio, ruggedness and relatively low cost. In last few decade, the induction motor has involve from being a constant speed motor to a variable speed, variable torque machine. The induction motor is robust, smaller in size, almost maintenance free and possess a wide range of speed when compare to DC motor. Their mechanical dependability is due to the reason that there is no requirement of mechanical commentator.

However, conventional control of an induction motor is difficult due to strong nonlinear magnetic saturation effects and temperature dependency of the motor's electrical parameters $[1,2]$. Generally, the conventional control approaches require a complex mathematical model of the motor to develop controllers for quantities such as speed, torque, and position [2, 3]. Modelbased calculations must be performed specifically for each motor, and the resulting modelbased controllers may not perform well if temperature change causes parameter values to change.

In order to achieve high performance and better controllability, vector control or field oriented control of induction motor drive should be employed [3-5]. By using this method, the induction motor can be controlled like a separately excited dc motor. This method enables the control of field and torque of the induction machine independently by manipulating the corresponding field oriented quantities.

Nevertheless, the motor performance will be degraded face to motor parameters variation or unknown external disturbances $[6,7]$. To offer control robustness with minimum complexity many strategies have been proposed in literature $[8,9]$. In $[6,10]$ fuzzy logic controller were used to realize the robustness of the controller for high performance of induction motor drive system.

Fuzzy logic controller (FLC) has been proposed for speed control in vector control of induction motor drives in [11,12]. The most common fuzzy logic controllers are based on constant parameter fuzzy logic (CPFL) [13]. The CPFL controller has already been successfully implemented in high performance vector controlled drive [14]. The CPFL controller has two inputs that are speed error and change of speed error. The output of the CPFL controller is a torque current command which need to be increased or decreased according to the speed error and change in speed error. Numerous researchers have used an off-line optimized CPFL 
technique [4], [14-15]. This technique is used to tune the membership functions, fuzzy rules and scaling factors based on trial and error until desired response is obtained. The desired response means that the response which has short settling time and zero overshoot. However, tuning FLC is more difficult than tuning a conventional PI. A FLC has more than two parameters which can be adjusted and that can lead to a different behavior of the controlled process.

Furthermore, tuning of scaling factors is very important because a change of scaling factors can affect the stability, oscillation and damping of the system [2]. Therefore, some researchers have proposed a design case CPFL (DCCPFL) to minimize the difficulty associated with trial and error approach to scaling factors tuning $[13,16]$. The DCCPFL controller is based on the controller designed in off-line optimized CPFL and the scaling factors are calculated using known motor data $[2,17]$.

This paper studies the effect of parameters variation such as rotor resistance, $R_{r}$, inertia, $\mathrm{J}$ and self-inductance of the rotor, Linconventional PI speed controllerand DCCPFL.

\section{Vector Control of Three Phase Induction Motor}

The mathematical model of the three-phase squirrel cage induction motor in synchronously rotating reference can be expressed [18] as (1-8):

$$
\begin{aligned}
& V_{q s}=R_{s} i_{q s}+\frac{d \varphi_{q s}}{d t}+\omega_{e} \varphi_{d s} \\
& V_{d s}=R_{s} i_{d s}+\frac{d \varphi_{d s}}{d t}-\omega_{e} \varphi_{q s} \\
& V_{q r}=R_{r} i_{q r}+\frac{d \varphi_{q r}}{d t}+\left(\omega_{e}-\omega_{r}\right) \varphi_{d r} \\
& V_{d r}=R_{r} i_{d r}+\frac{d \varphi_{d r}}{d t}+\left(\omega_{e}-\omega_{r}\right) \varphi_{q r}
\end{aligned}
$$

And the flux equations are:

$$
\begin{aligned}
& \varphi_{q s}=L_{L s} i_{q s}+L_{m}\left(i_{q s}+i_{q r}\right) \\
& \varphi_{q r}=L_{l r} i_{q r}+L_{m}\left(i_{q s}+i_{q r}\right) \\
& \varphi_{d s}=L_{l s} i_{d s}+L_{m}\left(i_{d s}+i_{d r}\right) \\
& \varphi_{d r}=L_{l r} i_{d r}+L_{m}\left(i_{d s}+i_{d r}\right)
\end{aligned}
$$

In this equations, the various symbols denote the following: $V_{q s}$ and $V_{d s}$ are theapplied voltages to the stator; $i_{d s}, i_{q s}, i_{d r}$, and $i_{q r}$, the corresponding $\mathrm{d}$ and $q$ axis stator currents and rotor currents; $\varphi_{q s}, \varphi_{q r}, \varphi_{d s}, \varphi_{d r}$, are the stator and rotor flux component; $R_{s}, R_{r}$ are the stator and rotor resistances; $L_{l s}, L_{l r}$ indicatesself-inductancesstator and rotor respectively, whereas $L_{m}$ is the mutual inductance. The electromagnetic torque equation of the induction motor is given by:

$$
T_{e}=\frac{3}{2} \frac{P}{2} \frac{L_{m}}{L_{r}}\left(\varphi_{d r} i_{q s}-\varphi_{q r} i_{d s}\right)
$$

$P$ indicates the pole number of the motor. If the vector control is fulfilled, the $q$-axis component of the rotor field $\varphi_{g r}$ would be zero. Then the electromagnetic torque is controlled only by q-axis stator current and becomes: 


$$
T_{e}=\frac{3}{2} \frac{P}{2} \frac{L_{m}}{L_{r}}\left(\varphi_{d r} i_{q s}\right)
$$

The rotor flux quantities are estimated using computational rotor time constant, rotor angular velocity and stator current as in (11).

$$
\frac{d \theta_{e}}{d t}=\frac{1}{\operatorname{Tr}} \frac{i_{q s}}{i_{d s}}+\omega_{r}
$$

Figure 1 shows the block diagram of vector control induction motorwith hysteresis current controller using FLC. The $d$-axis current reference $i_{d s}^{*}$, can be calculated from the flux command $\varphi_{d r}^{*}$ denotes the right rotor flux command for every speed reference within the nominal value. The rotor speed reference $\omega_{m}^{*}$ is compared with measured rotor speed $\omega_{m}$ and FLC processed the resulting error toproduce $q$-axis reference current $i_{q s}^{*}$. Both $i_{d s}^{*}$ and $i_{q s}^{*}$ are converted to three phase stationary reference frame through Inverse Park's Transformation and compared to the current from the feedback of the motor. Then the current errors are fed to hysteresis current controllers which generate switching signal for the inverter. The Simulink model of vector control of induction motor is shown in Figure 2.

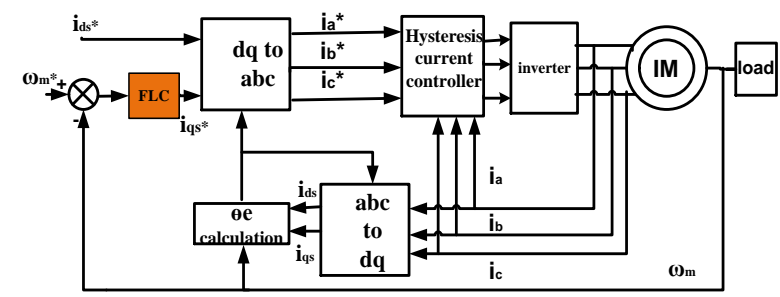

Figure 1. Indirect vector control with hysteresis current band

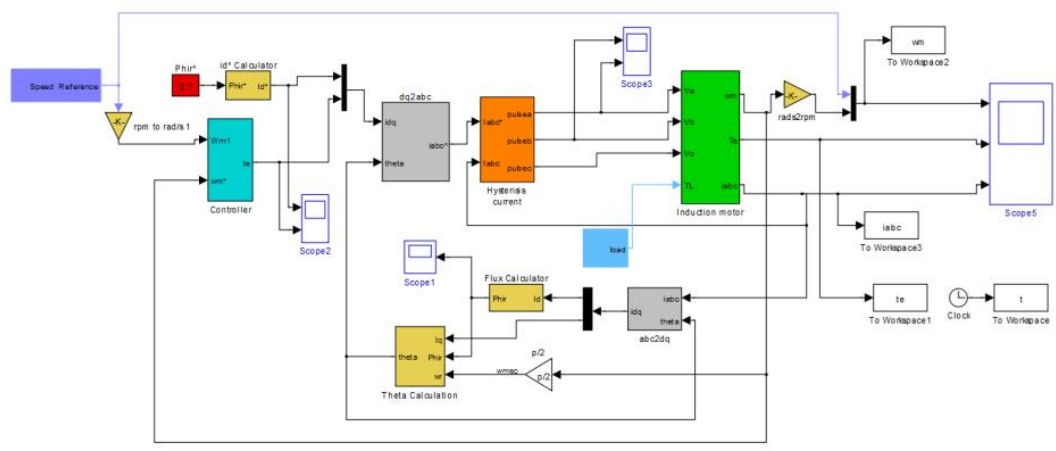

Figure 2. Simulink block diagram of induction motor drives system

\section{Fuzzy Logic Controller}

The structure of FLC consists of the input linguistic variables; the speed error, $e$ and change in speed error,ce and the output linguistic variable; the torque producing current component, $i_{q s}{ }^{*}$. Figure 3Figure 3 shows the structure of FLC. The correlation function of FLC can be expressed as [4]

$$
i_{q}(n)=\int_{\text {discrete }} \Delta i_{q}(n)=f\left(\Delta e(n), \Delta \omega_{m}(n)\right)
$$

Where, the change of speed error can be written as,

TELKOMNIKA Vol. 16, No. 2, November 2015: $272-280$ 


$$
\Delta e(n)=\Delta \omega_{m}(n)-\Delta \omega_{m}(n-1)
$$

The present sample of speed error is:

$$
\Delta \omega_{m}(n)=\omega_{m}^{*}(n)-\omega_{m}(n)
$$

$\omega_{m}(n)$ is motor actual speed, $\omega_{m}^{*}(n)$ is past sample of reference speed and $f$ represents the nonlinear function.

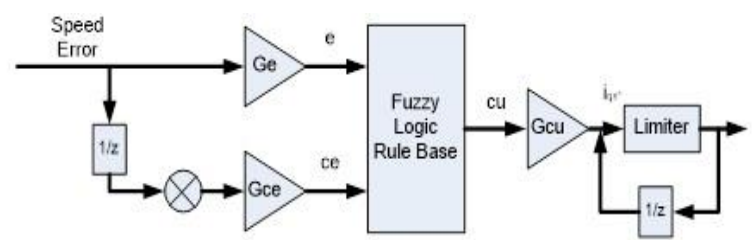

Figure 3. Structure of Fuzzy Logic Controller

\subsection{DCCPFL}

Based on DCCPFL, $G_{c e}$ and $G_{e}$ are calculated using known motor data. Rated speed of the motor is 1300rpm and an assumption is made that this value is the maximum speed of operation of the motor. Thus, maximum speed error is $136.1357 \mathrm{rad} / \mathrm{s}$ for start-up from standstill and the scaling factor for the speed error is obtained as [2, 19]:

$$
\mathrm{G}_{\mathrm{e}}=\frac{1}{136.1357}=0.0073456
$$

The scaling factor for the change in speed error is calculated on the basis of rated inertia and maximum torque that the motor is allowed to develop, taking sampling time $20 \mu$ s.

$$
\operatorname{Temax}=\frac{J_{n}}{p}\left(\frac{\Delta \omega}{T_{S}}\right)
$$

Then,

$$
\Delta \omega=0.2458
$$

Therefore,

$$
\mathrm{G}_{\mathrm{ce}}=\frac{1}{c e}=\frac{1}{\Delta \omega}=4.069 .
$$

Output scaling factor is set to $\mathrm{G}_{\mathrm{cu}}=2$.

\subsection{Rule Base}

Mamdani's type of rule has been used in this work because it can provide a natural framework to convert the human knowledge into fuzzy "IF....THEN rules. These statements governing the relationship between inputs and outputs variables in terms of membership functions. In this stage the input variables $e$ and ce are processed by the inference engine that implements the rule base of 49 rules presented in Table 1. The linguistic terms used for inputs and output variables are defined as: NL is Negative Large, NM is Negative Medium, NS is Negative Small, ZE is Zero Error, PS is Positive Small, PM is Positive Medium and PL is Positive Large. 
Table 1. Rule Base for FLC

\begin{tabular}{llllllll}
\hline ce & $\mathrm{NL}$ & $\mathrm{NM}$ & $\mathrm{NS}$ & $\mathrm{ZE}$ & $\mathrm{PS}$ & $\mathrm{PM}$ & $\mathrm{PL}$ \\
$\mathrm{e}$ & & & & & & & \\
\hline $\mathrm{NL}$ & $\mathrm{NL}$ & $\mathrm{NL}$ & $\mathrm{NL}$ & $\mathrm{NL}$ & $\mathrm{NM}$ & $\mathrm{NS}$ & $\mathrm{ZE}$ \\
$\mathrm{NM}$ & $\mathrm{NL}$ & $\mathrm{NL}$ & $\mathrm{NL}$ & $\mathrm{NM}$ & $\mathrm{NS}$ & $\mathrm{ZE}$ & $\mathrm{PS}$ \\
$\mathrm{NS}$ & $\mathrm{NL}$ & $\mathrm{NL}$ & $\mathrm{NM}$ & $\mathrm{NS}$ & $\mathrm{ZE}$ & $\mathrm{PS}$ & $\mathrm{PM}$ \\
$\mathrm{ZE}$ & $\mathrm{NL}$ & $\mathrm{NM}$ & $\mathrm{NS}$ & $\mathrm{ZE}$ & $\mathrm{PS}$ & $\mathrm{PM}$ & $\mathrm{PL}$ \\
$\mathrm{PS}$ & $\mathrm{NM}$ & $\mathrm{NS}$ & $\mathrm{ZE}$ & $\mathrm{PS}$ & $\mathrm{PM}$ & $\mathrm{PL}$ & $\mathrm{PL}$ \\
$\mathrm{PM}$ & $\mathrm{NS}$ & $\mathrm{ZE}$ & $\mathrm{PS}$ & $\mathrm{PM}$ & $\mathrm{PL}$ & $\mathrm{PL}$ & $\mathrm{PL}$ \\
$\mathrm{PL}$ & $\mathrm{ZE}$ & $\mathrm{PS}$ & $\mathrm{PM}$ & $\mathrm{PL}$ & $\mathrm{PL}$ & $\mathrm{PL}$ & $\mathrm{PL}$ \\
\hline
\end{tabular}

\subsection{Membership Function}

The standard membership functions used for DCCPFLis shown in Figure 4. Seven triangular membership functions are used to denote the input and output FLC variables. The triangular membership functions are designed to be symmetrical and identical in terms of width and peak position.

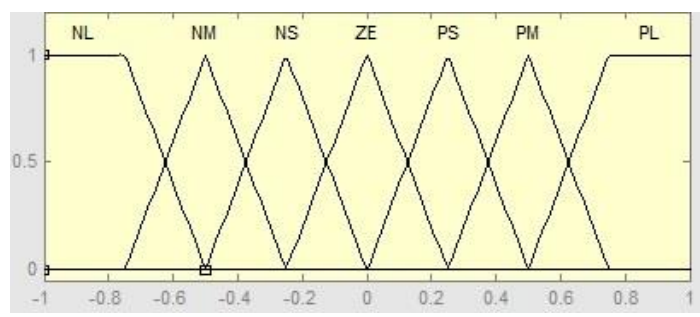

Figure 4. Standard membership functions for SCPFL and DCCPFL

\subsection{Defuzzification}

Generally the output of fuzzy controller has to be translated into a crisp value by using defuzzification technique. In this work, the center of area (CoA) method is used.

\section{Simulation Results}

Several simulation tests of FLC and PI controller based vector control of induction motor were presented using MATLAB/SIMULINK. The motor used in the simulation is $415 \mathrm{~V}, 3$ phase squirrel cage induction motor with a $1.5 \mathrm{~kW}$ rated power. The parameters of the motor are given in Table 2.

Table 2. Induction motor parameters

\begin{tabular}{ll}
\hline Parameter & Value \\
\hline Stator resistance, $\mathbf{R}_{\mathbf{s}}$ & $4.6 \Omega$ \\
Rotor resistance, $\mathbf{R}_{\mathbf{r}}$ & $5.66 \Omega$ \\
Stator inductance, $\mathrm{L}_{\mathbf{s}}$ & $0.3153 \mathrm{H}$ \\
Rotor inductance, $\mathrm{L}_{\mathbf{r}}$ & $0.3153 \mathrm{H}$ \\
Mutual inductance, $\mathrm{L}_{\mathbf{m}}$ & $0.3 \mathrm{H}$ \\
Moment of inertia, $\mathbf{J}$ & $0.004 \mathrm{Kgm}^{2}$ \\
Number of poles & 4 \\
\hline
\end{tabular}

Figure 5 shows the comparison of speed response of PI controller and DCCPFL with a reference speed of $1300 \mathrm{rpm}$ underrated conditions. The PI controllers shows an overshoot and takes longer time to achieve a steady statecompared to DCCPFL. 


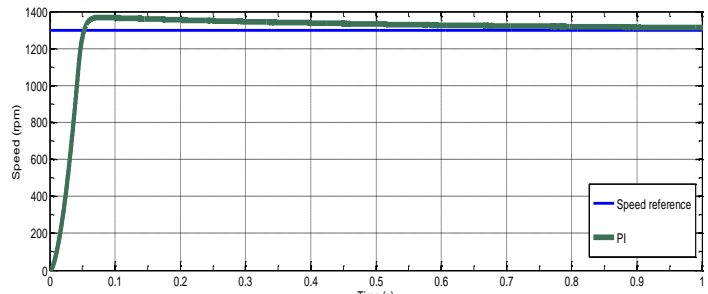

(a)

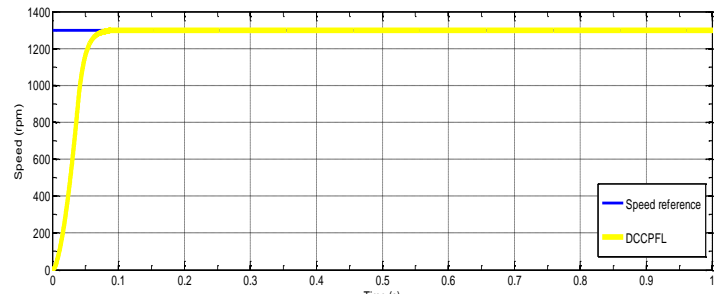

(b)

Figure 5. Speed response of the drive with rated conditions (a) PI controller (b) DCCPFL controller

Figure 6(a) and Figure 6(b) give the results of speed response using PI controller and DCCPFL respectively which considering the changes of rotor resistance value, $R_{r}$. When $R_{r}$ was reduced to half rated value, the results show the increasing of delay and rise time of speed response compared to rated $R_{r}$ and double rated $R_{r}$. But, to achieve steady state DCCPFL shows better performance. It is only take $0.1 \mathrm{~s}$ for DCCPFL compare to $\mathrm{PI}$ is 2.5 s even the value of $R_{r}$ was change.

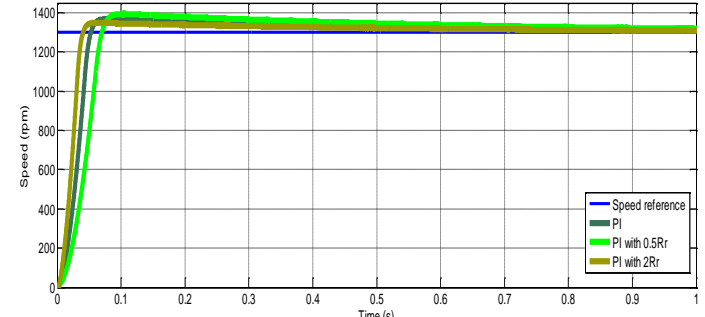

(a)

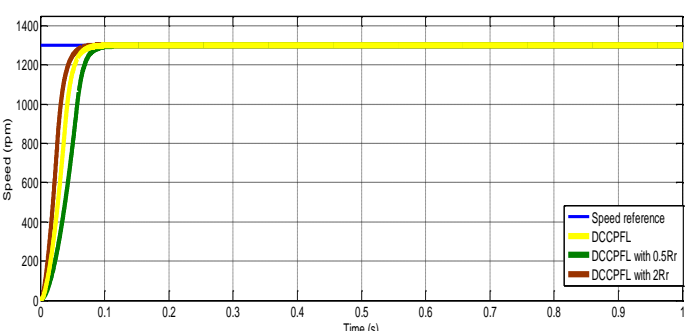

(b)

Figure 6. Speed response of the drive with parameter variation of rotor resistance, $\mathrm{R}_{\mathrm{r}}(\mathrm{a}) \mathrm{PI}$ controller (b) DCCPFL controller

In Figure 7 shows the effects of difference inertia applied to the motor. Figure 7 (a) shows the PI controller with double rated inertia contributed more time to rise the speed from zero to speed reference compare to rated value. Increase value of inertia also gave effect to DCCPFL controller as shown in Figure 7(b). Though the rise time of speed response is increase but the difference of the settling time is only $0.02 \mathrm{~s}$.

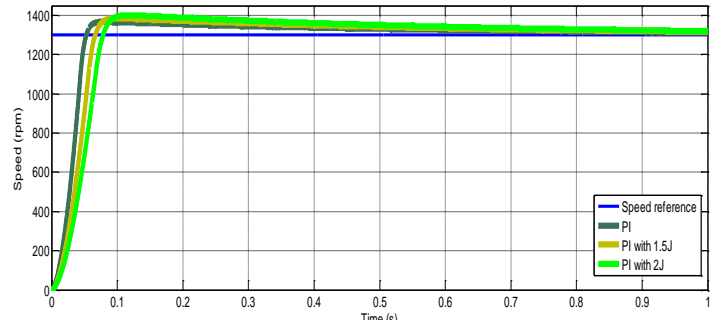

(a)

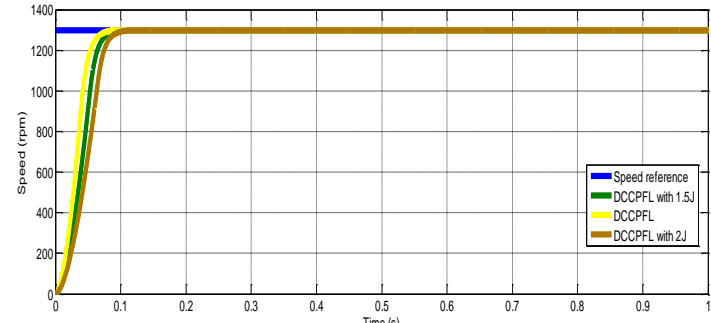

(b)

Figure 7. Speed response of the drive with parameter variation of inertia, J (a) PI(b) DCCPFL 
The simulation test with variation of self inductance rotor, $L_{r}$ is reported in Figure 8 for full rated, one and half rated and double rated value of $L_{r}$. The response of $\mathrm{PI}$ controller as Figure 8(a) shows that when the value of $L_{r}$ changed the transient performance degraded. Speed response for $\mathrm{PI}$ with rated value shows a speed overshoot of $5 \%$ compared to $7 \%$ and $9 \%$ of one and half rated and double rated value of $L_{r}$. These three variation values of $L_{r}$ show settling time as 2.5s, 2.57sand 2.63s respectively. DCCPFL controller as Figure 8 (b) shows no overshoot for three different value of $L_{r}$. For rated value, one and half rated value and double rated value are $0.11 \mathrm{~s}, 0.12 \mathrm{~s}$ and $0.14 \mathrm{~s}$ respectively. It shown that escalation value of $L_{r}$ give effect to the rise time of both controller.

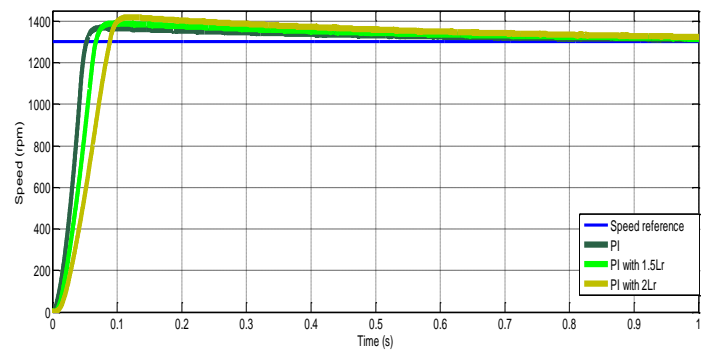

(a)

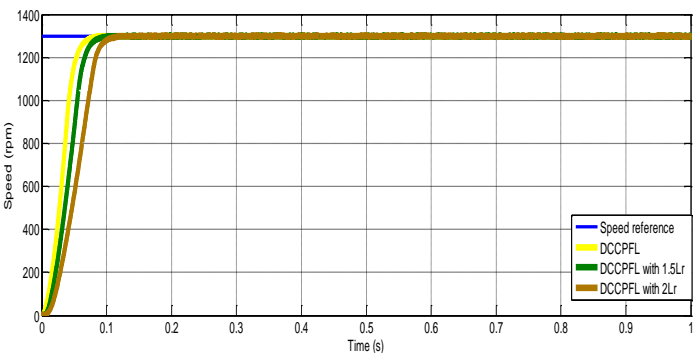

(b)

Figure 8. Speed response of the drive with parameter variationof self inductance rotor, $L_{r}$ a) $P I$ controller b) DCCPFL

In addition, the performance of parameter variations for both controllers also tested for load disturbance with half rated load $5 \mathrm{~N} / \mathrm{m}$. Figure 9 shows load disturbance rejection with different value of $R_{r}$. For PI controller as given in Figure 9(a), three value of $R_{r}$ perform almost same responded at $\mathrm{t}=3 \mathrm{~s}$ the speed drop to $1254 \mathrm{rpm}$ and after $2.4 \mathrm{~s}$ speed response adjusted back to the speed command 1300rpm. Conversely, DCCPFL gave better performance as presented in the Figure 9(b). When load is given at $3 \mathrm{~s}$ for double, full and half rated of $R_{r}$, the speed decline to 1297.1rpm, 1297.3rpm and 1297.1rpm, respectively. Moreover, the settling time of load disturbance rejection are very fast. It is only take $0.025 \mathrm{~s}$ to follow the speed command.

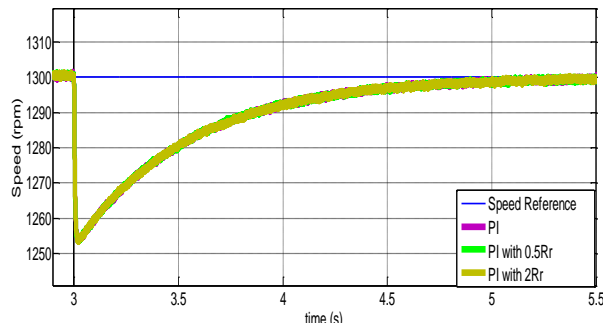

(a)

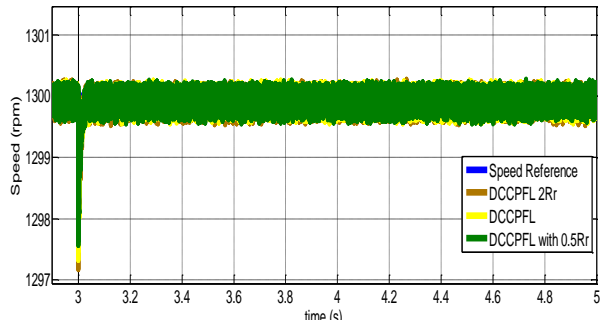

(b)

Figure 9. Load disturbance rejectionwith parameter variation of rotor resistance, $R_{r}$ at half rated load $5 \mathrm{~N} / \mathrm{m}$ a) PI controller b) DCCPFL

Figure 10 shows load disturbance rejection with three different value of inertia, J. In Figure 10(a) indicates that in PI controller, a small changes occurred while increase the inertia value.The speed drip to 1254rpm. It takes $2.2 \mathrm{~s}$ to reject disturbance. In comparison with DCCPFL as in Figure 10 (b), the speed for rated inertia was dip to $1297.3 \mathrm{rpm}$ and others two aresame1297.9 rpm. The settling time for rejection disturbance of those values are $0.022 \mathrm{~s}$.

TELKOMNIKA Vol. 16, No. 2, November $2015: 272-280$ 


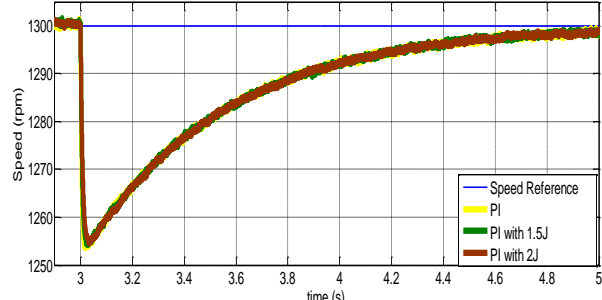

(a)

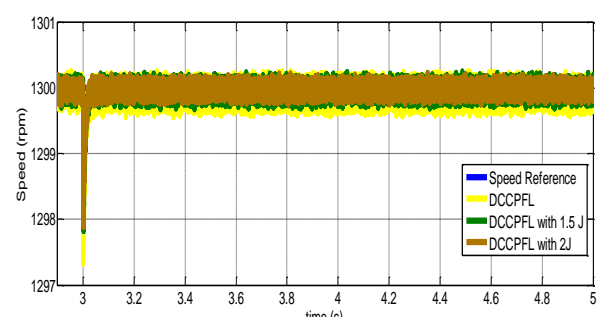

(b)

Figure 10. Load disturbance rejection with parameter variation of inertia, Jat half rated load $5 \mathrm{~N} / \mathrm{m}$ a) PI controller b) DCCPFL

Finally, the simulation test is done for load disturbance rejection with three different value of self-inductance rotor, $L_{r}$. In Figure 11(a) shows the speed response of PI controller. There are three different transient response occurred for one and half rated, full and double rated value of $L_{r}$. The lowest speed shot to1208rpm for double rated $L_{r}$ compared to one and half rated, $1230 \mathrm{rpm}$ and full rated, $1254 \mathrm{rpm}$. The speed response of DCCPFL controller as shown in Figure 11(b) gave better response compared to PI controller. For double rated $\mathrm{L}_{r}$, the speed dip to $1276 \mathrm{rpm}$ and both half and full rated $\mathrm{L}_{\mathrm{r}}$ are $1287 \mathrm{rpm}$ and $1297 \mathrm{rpm}$, respectively. In addition, the settling time to achieve steady state for each $L_{r}$ was different. The duration for settle down the disruption of load for full rated $L_{r}$ was $0.018 \mathrm{~s}$. However, when the $L_{r}$ was increased up to $50 \%$, the settling time was shorter than full rated $L_{r}$ which was $0.004 \mathrm{~s}$. But when the value of $L_{r}$ was doubled the rejection time was $0.03 \mathrm{~s}$. Thus, the effect of $L_{r} v a r i a t i o n s$ is very small tothe performance of DCCPFL controller.

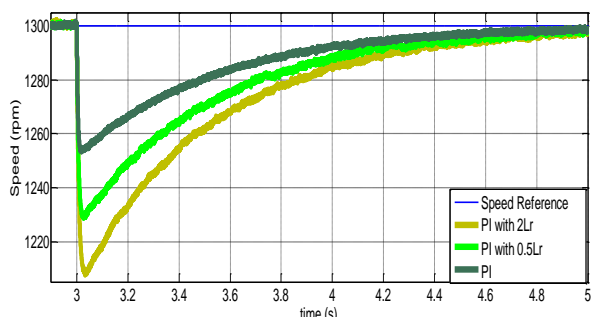

(a)

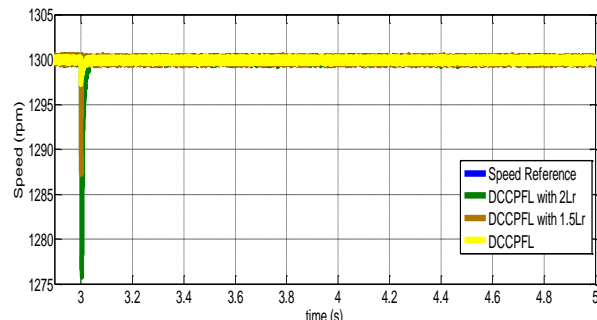

(b)

Figure 11. Load disturbance rejection with parameter variation of self-inductance rotor, $L r$ at half rated load $5 \mathrm{~N} / \mathrm{m}$; a) PI controller b) DCCPFL

\section{Conclusion}

In this paper the influence of parameter variations is investigated forDCCPFL and conventional $\mathrm{PI}$ controller of vector controlled induction motor drives in simulation environment. For Fuzzy Logic Controller, the DCCPFL is choose because of the easy way to get the scaling factors value by calculate it from the known motor data. The drives performance has been evaluated under load disturbance and different parameters. From this study, it can be concluded that parameters variation give minimum effect to DCCPFL compare to conventional PI controller. It is shown from the simulation results that DCCPFL gave better performance in term of faster time to achieve steady state and to settle disturbance rejection. Thus, the DCCPFL shows its robustness against load disturbance and parameter changes.

\section{References}

[1] Spiegel RJ, Turner MW, Mccormick VE. Fuzzy-logic-based controllers for efficiency optimization of inverter-fed induction motor drives. Fuzzy Sets and Systems. 2003; 137: 387-401. 
[2] Kumar B, Chauhan YK, Shrivastava V. Efficacy of Different Rule Based Fuzzy Logic Controllers for Induction Motor Drive. International Journal of Machine Learning and Computing. 2012; 2(2): 131-137.

[3] Sahu B, Mohanty K, Pati S. A comparative study on fuzzy and PI speed controllers for field-oriented induction motor drive. Modern Electric Power Systems (MEPS), Proceedings of the International Symposium, IEEE. 2010. p. 1-7.

[4] Uddin MN, Radwan TS, Rahman MA. Performances of Fuzzy-Logic-Based Indirect Vector Control for Induction Motor Drive. IEEE Transactions on Industry Applications. 2002; 38(5): 1219-1225.

[5] Panchade VM, Chile $\mathrm{RH}$, Patre BM. A survey on sliding mode control strategies for induction motors. Annual Reviews in Control. 2013; 37(2): 289-307.

[6] Rafa S, Larabi A, Barazane L, Manceur M, Essounbouli N, Hamzaoui A. Fuzzy vector control of induction motor. In Networking, Sensing and Control (ICNSC), 2013 10th IEEE International Conference, IEEE. 2013: 815-820.

[7] Shiri a, Vahedi A, Shoulaie A. The effect of parameter variations on the performance of indirect vector controlled induction motor drive. In 2006 5th IEEE International Power Electronics and Motion Control Conference. 2006: 1-5.

[8] Li J, Ren HP, Zhong YR. Robust speed control of induction motor drives employing first-order autodisturbance rejection controllers. IEEE Transaction on Industry Applications. 2015; 51(1): 712-720.

[9] Menghal PM, Laxmi AJ. Artificial Intelligence Based Dynamic Simulation of Induction Motor Drives. IOSR Journal of Electrical and Electronics Engineering (IOSR-JEEE). 2012; 3(5): 37-45.

[10] Kar BN, Mohanty KB, Singh M. Indirect vector control of induction motor using fuzzy logic controller. In 2011 10th International Conference on Environment and Electrical Engineering, IEEE. 2011: 1-4.

[11] Kumar R, Gupta RA, Bhangale SV. Indirect vector controlled induction motor drive with fuzzy logic based intelligent controller. IET-UK International Conference on Information and Communication Technology in Electrical Sciences (ICTES 2007), IEEE. 2007; 368-373.

[12] Kaletsanos A, Xepapas F, Manias SN. A novel nonlinear and intelligent control technique for induction motor drive systems. Conference Record of the 2004 IEEE Industry Applications Conference, 2004 39th IAS Annual Meeting, IEEE. 2004: 1335-1341.

[13] Ibrahim Z. Fuzzy Logic Control of PWM Inverter-Fed Sinusoidal Permanent Magnet Synchronous Motor Drives. Thesis. Liverpool: John Moores University; 1999.

[14] Arulmozhiyal R, Baskaran K, Manikandan R. An intelligent speed controller for indirect vector controlled induction motor drive. In Computational Intelligence and Computing Research (ICCIC), 2010 IEEE International Conference, IEEE. 2010: 1-5.

[15] Lazi JM, Ibrahim Z, Sulaiman M, Patakor FA, Mat Isa SN. Fuzzy Logic Speed Controller with Reduced Rule Base for Dual PMSM Drives. In World Academy of Science, Engineering and Technology. 2011. p. 252-7.

[16] Li H. A comparative design and tuning for conventional fuzzy control. IEEE Transactions on Systems, Man, and Cybernetics-Part B: Cybernetics. 1997; 27(5): 884-889.

[17] Ibrahim Z, Levi E. A comparative analysis of fuzzy logic and PI speed control in high performance AC drives using experimental approach. Conference Record of the 2000 IEEE Industry Applications Conference Thirty-Fifth IAS Annual Meeting and World Conference on Industrial Applications of Electrical Energy (Cat No00CH37129). 2000; 2(5): 1210-1218.

[18] Sulaiman M, Patakor FA, Ibrahim Z. A New State-Dependent of Sliding Mode Control for Three-Phase Induction Motor Drives. International Review on Modelling and Simulations (IREMOS). 2013; 6(3): 728-735.

[19] Mat Isa SN, Ibrahim Z, Patkar F. Comparative study of fuzzy logic speed controller in vector controlled PMSM drive: Minimum number of fuzzy rule-base. In 2009 Innovative Technologies in Intelligent Systems and Industrial Applications, CITISIA 2009. 2009: 112-118.

TELKOMNIKA Vol. 16, No. 2, November 2015: $272-280$ 